\title{
Hypoxia: good guy or bad guy?
}

\author{
Martin Burtscher • Nikolaus C. Netzer
}

Published online: 20 May 2010

(C) Springer-Verlag 2010

The present issue of "Sleep and Breathing" provides several lines of evidence for beneficial applications of exposure to hypoxic environments. This seems to contrast with the general experience that hypoxia is a constant threat to the human organism throughout life. Multiple hypoxic situations may occur in health and disease, but mechanisms have developed to protect the human body and its vital organs from detrimental effects of hypoxia. As demonstrated by the articles in this issue of "Sleep and Breathing" the specific use of such mechanisms might even have the potential of preventive or therapeutic effects. Despite a wealth of research work, it is not well understood why sometimes hypoxia is harmful and sometimes beneficial. Types of exposures and individual responses to hypoxia are so multifaceted that much more systematic research will be necessary to find conclusive answers. Nevertheless, sometimes hypoxia is undoubtedly a bad guy as it is the case at very high altitude, in obstructive sleep apnea or in severe chronic obstructive pulmonary disease (COPD) [1-3]. However, there are also examples for hypoxia as a good guy, e.g., the planned exposures to hypoxia have been proved to support the high-altitude acclimatization or preacclimatization processes $[4,5]$. Additionally, it more and more turns out that the specific application of hypoxic exposures may be capable of provoking beneficial meta-

M. Burtscher $(\bowtie) \cdot$ N. C. Netzer

Department of Sport Science, Medical Section,

University of Innsbruck,

Fürstenweg 185,

6020 Innsbruck, Austria

e-mail: Martin.Burtscher@uibk.ac.at bolic changes in patients with metabolic syndrome or diabetes or might increase exercise tolerance in patients with coronary artery disease or COPD [6-8]. We are hopeful that the ongoing interdisciplinary research will extend our knowledge on the good and bad guy aspects of hypoxia and promote better understanding when and why hypoxia is beneficial and when and why it is detrimental.

\section{References}

1. Hackett PH, Roach RC (2001) High-altitude illness. N Engl J Med 345:107-114

2. Arnardottir ES, Mackiewicz M, Gislason T, Teff KL, Pack AI (2009) Molecular signatures of obstructive sleep apnea in adults: a review and perspective. Sleep 32:447-470

3. Chaouat A, Naeije R, Weitzenblum E (2008) Pulmonary hypertension in COPD. Eur Respir J 32:1371-1385

4. Schoene RB (2008) Illnesses at high altitude. Chest 134:402-416

5. Burtscher M, Brandstätter E, Gatterer H (2008) Preacclimatization in simulated altitudes. Sleep Breath 12:109-114

6. Schobersberger W, Schmid P, Lechleitner M, von Duvillard SP, Hörtnagl H, Gunga HC, Klingler A, Fries D, Kirsch K, Spiesberger R, Pokan R, Hofmann P, Hoppichler F, Riedmann G, Baumgartner H, Humpeler E, Austrian Moderate Altitude Study 2000 (AMAS 2000) (2003) The effects of moderate altitude $(1,700 \mathrm{~m})$ on cardiovascular and metabolic variables in patients with metabolic syndrome. Eur J Appl Physiol 88:506-514

7. Netzer NC, Chytra R, Küpper T (2008) Low intense physical exercise in normobaric hypoxia leads to more weight loss in obese people than low intense physical exercise in normobaric sham hypoxia. Sleep Breath 12:129-134

8. Burtscher M, Haider T, Domej W, Linser T, Gatterer H, Faulhaber M, Pocecco E, Ehrenburg I, Tkatchuk E, Koch R, Bernardi L (2009) Intermittent hypoxia increases exercise tolerance in patients at risk for or with mild COPD. Respir Physiol Neurobiol 165:97-103 